\title{
„Haute Couture für Bücher" auf der Landesgartenschau 2016 in Öhringen
}

Eine Ausstellung der Württembergischen Landesbibliothek vom 25. Mai bis 5. Juni 2016

Der Öhringer Bürgermeister Erich Herrmann zeigte sich bei der Eröffnung der Ausstellung „Haute Couture für Bücher - Einbandkunst in der Württembergischen Landesbibliothek" am 25. Mai 2016 erstaunt, dass so zahlreiche Menschen in den Treffpunkt Baden-Württemberg (TBW) kamen. Nahezu 100 Personen hatten sich von der schlechten Wetterprognose nicht abhalten lassen und nahmen an der kurzweiligen Eröffnung teil.

Frau Sylvie Kostic vom TBW begrüßte die Gäste, Karl Albrecht Fischer am Piano und Markus Bodenseh am Bass übernahmen die musikalische Unterhaltung, und Herr Dr. Hannsjörg Kowark, Direktor der Württembergischen Landesbibliothek, eröffnete die Ausstellung. Anschließend lud der TBW zum Stehempfang ein.

Der TBW auf der Landesgartenschau in Öhringen befindet sich im ehemaligen Hoftheater, einem

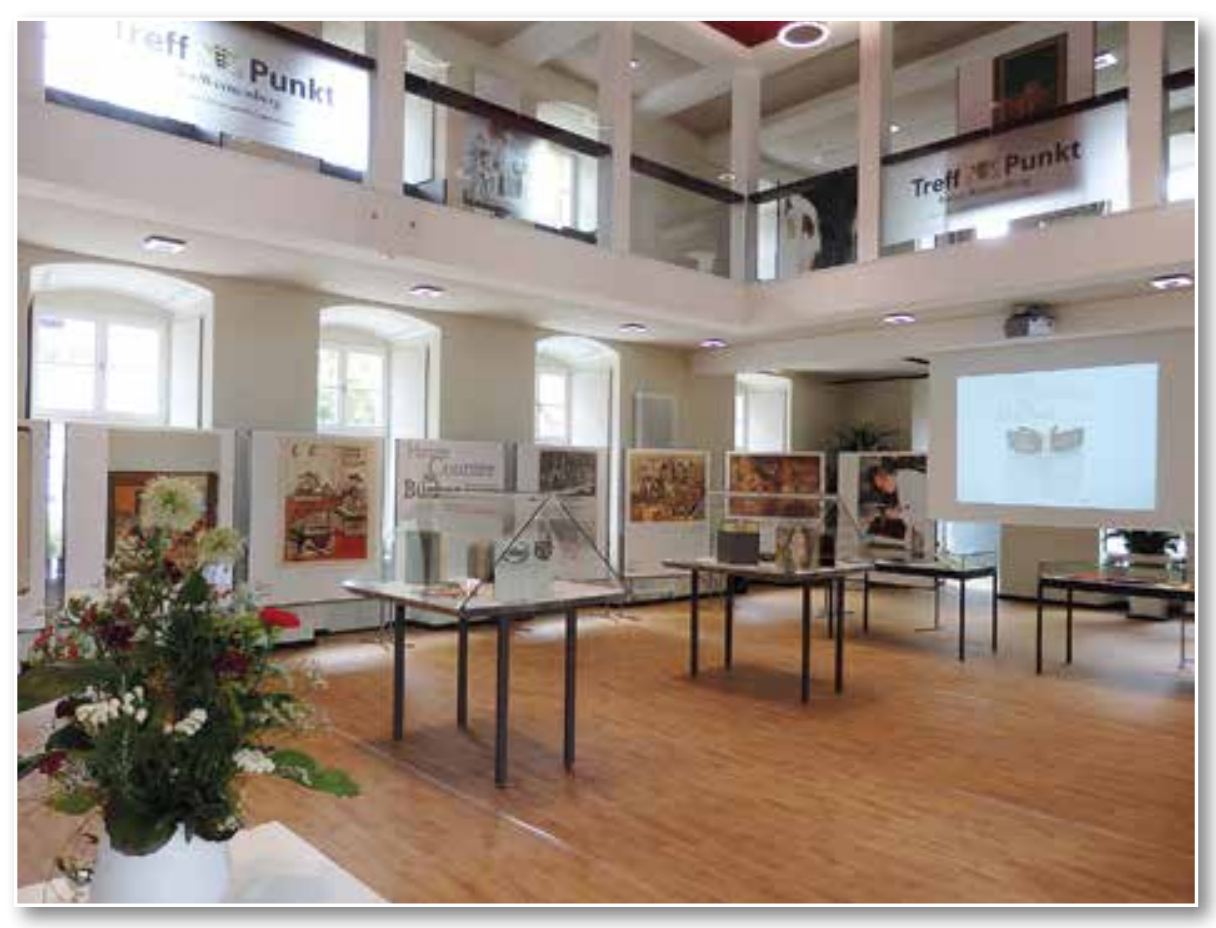

Abb. 1: Blick in die Ausstellung erst vor Kurzem aufwendig renovierten Bau aus der Mitte des 18. Jahrhunderts. Das Erdgeschoss, ursprünglich als Orangerie genutzt, und die Galerie im ersten Stockwerk bildeten einen idealen Raum für die Präsentationen der WLB mit Displays, Tischvitrinen, IT-Stelen und praktischen Vorführungen.

Neben den Kollegen und Kolleginnen der WLB, die Beispiele aus der Restaurierungspraxis zeigten, Erläuterungen zur bibliothekarischen Erfassung von Bucheinbänden gaben oder historische Hefttechniken an der Buchbinderlade vorführten, präsentierten Meister und Meisterinnen der Einbandkunst und Restauratoren und Restauratorinnen, die zum Teil schon lange Jahre mit der WLB verbunden sind, ihre Arbeitsschwerpunkte. Zu großem Dank verpflichtet ist die WLB Herrn Buchbindermeister Hans-Peter Frölich, Mitglied der Buchbinderdynastie Frölich in Stuttgart und ehemaliger Präsident der Internationalen Vereinigung der Meister der Einbandkunst, Herrn Buchbindermeister Rudolf Schiller, Lehrlingswart und Meister der Einbandkunst, Stuttgart-Weilimdorf, den Bucheinbandgestalterinnen und -restauratorinnen Judith Schumann und Simone Püttmann, Stuttgart, Herrn Matthias und Frau Tina Raum, Werkstatt für Buchund Papierrestaurierung, Römerstein, sowie Herrn Norbert Schempp, Schempp Bestandserhaltung $\mathrm{GmbH}$ Kornwestheim.

Das Interesse der Besucher und Besucherinnen war unterschiedlich, einige kamen gezielt, um Buchbinderkollegen und -kolleginnen zu treffen oder Fragen zur Buchrestaurierung stellen zu können, 
andere, um einfach schöne Bücher zu sehen und wieder andere wurden durch das schöne Gebäude angezogen und nahmen die Präsentation der größten wissenschaftlichen Bibliothek Baden-Württembergs erstaunt zur Kenntnis. Dabei stießen die IT-Stelen und die Leder- und Pergamentproben zum Angreifen auf besonderes Interesse. Unter den Gästen waren erstaunlich zahlreiche Dauerkartenbesitzer, welche die Ausstellung häufig aufsuchten.
Einziger Wermutstropfen: Aufgrund des starken Regens und Unwetters kamen leider weniger Landesgartenschaubesucher und -besucherinnen als gewöhnlich.

Die nächste Landesgartenschau findet 2018 in Lahr statt. Die Direktion hat die Teilnahme der WLB bereits signalisiert.

Vera Trost

Abb. 2: Vera Trost zeigt das Heften an der Buchbinderlade
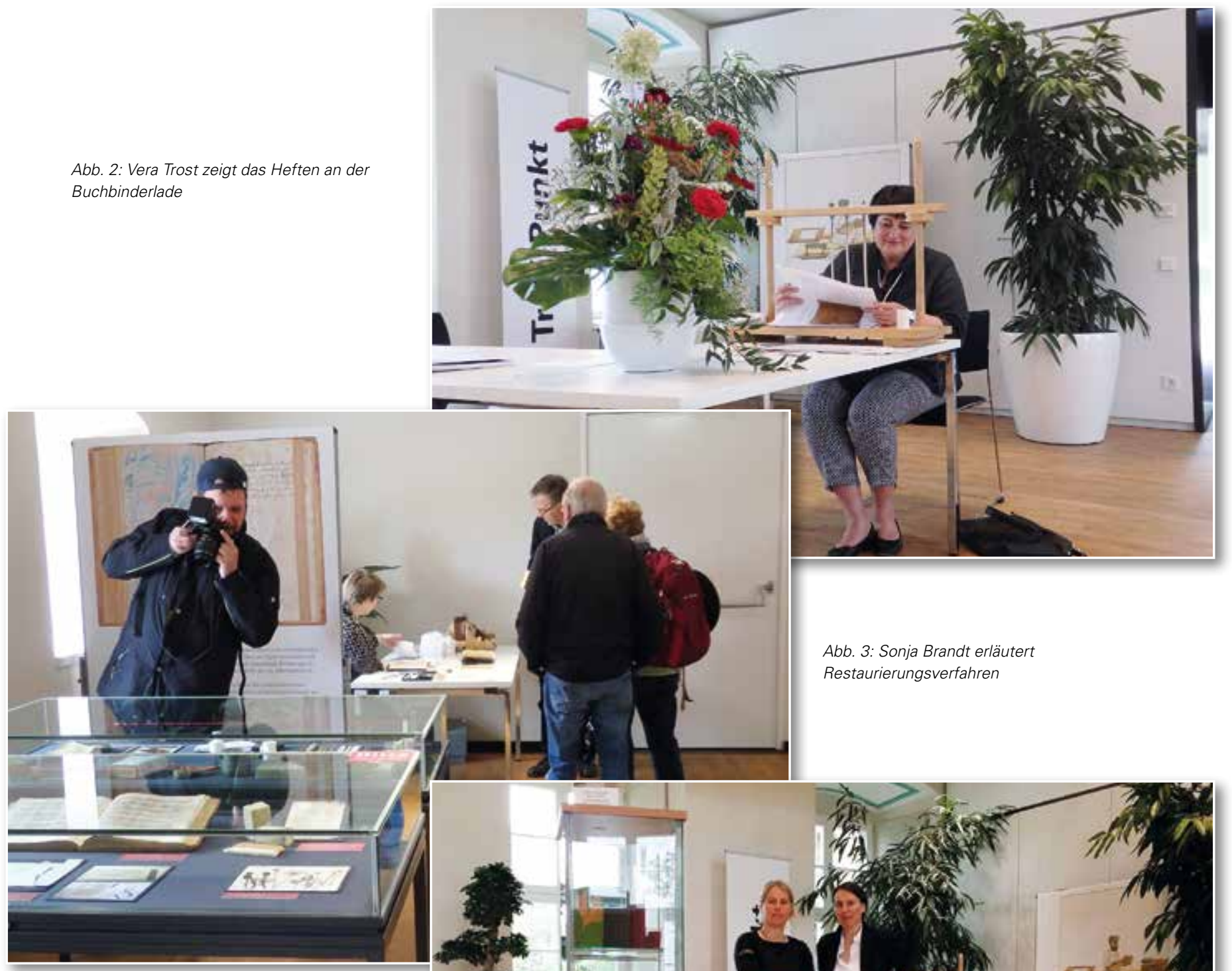

Abb. 4: Simone Püttmann und Judith Schumann 